\title{
COMPARING THE EFFECTS OF MODIFYING MiLLING TOOL GEOMETRY ON DURABILITY
}

\author{
Tomáš Kroupa, Václav Schorník,Milan Daňa, Miroslav Zetek \\ Reginal Technological Institute, University of West Bohemia, Faculty of Mechanical Engineering, \\ Univerzitní 8, Pilsen 30614
}

\begin{abstract}
Machining occupies a significant position in modern engineering technology and high quality parameters for it. To reduce production costs it is important to optimize the cutting process and rationalize production. If appropriate rationalization of the layout is implemented, it is possible to optimize cutting and other working conditions. In some milling operations such as grooving or roughing was observed, that when machining with an end mill tools with modified tips exhibit greater durability than tools without modification. Modifying is considered to be creation of chamfer or radius. The aim of this search is to compare two types of monolithic tools in terms of their durability. The tools differ from each other only in the modification tip edges. The main task is to verify the hypothesis that milling tools with a chamfered tip will have a higher durability and better stability in comparison with milling tools without this modification.
\end{abstract}

Keyword: Durability; End mill; Chamfer; Tool tip; Milling; Geometry
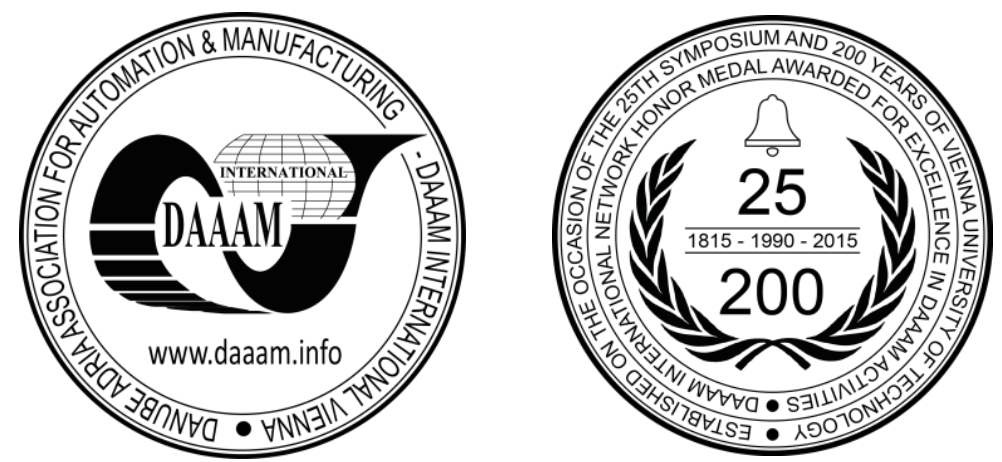

This Publication has to be referred as: Kroupa, T[omas]; Schornik, V[aclav]; Dana, M[ilan] \& Zetek, M[iroslav] (2016). Comparing the Effects of Modifying Milling Tool Geometry on Durability, Proceedings of the 26th DAAAM International Symposium, pp.0753-0761, B. Katalinic (Ed.), Published by DAAAM International, ISBN 978-3-90273407-5, ISSN 1726-9679, Vienna, Austria

DOI:10.2507/26th.daaam.proceedings.105 


\section{Introduction}

The experiment which is to verify if the observed effects are just random or whether they are systematic and could provide increase durability by suitable modifications of the tip edge. All existing research results can be taken into account that would somehow explain the possible relationship between durability and the modified tip edge.

Wear is a complicated process, when physical and chemical effects occur, changing the tool tip shape and its properties. The process leads to blunting which depends on many factors, such as the physical and mechanical properties of the tool and the machined material, tool geometry, operating conditions, and the type of operation. [1]

\begin{tabular}{|ll|}
\hline Nomenclature \\
$\mathrm{VB}$ & wear on the back \\
$\mathrm{T}$ & durability \\
$\mathrm{C}$ & carbon \\
$\mathrm{Mn}$ & manganese \\
$\mathrm{Si}$ & silicon \\
$\mathrm{P}$ & phosphorus \\
$\mathrm{S}$ & sulfur \\
$\mathrm{Cu}$ & copper \\
$\mathrm{Cr}$ & chrome \\
$\mathrm{Ni}$ & nickel \\
$\mathrm{a}_{\mathrm{max}}$ & maximum chip thickness \\
\hline
\end{tabular}

\section{The experiment}

The goal of the experiment is to compare the durability of two types of monolithic mills. Tools are made from cemented carbide and differ from each other in the modified geometry of the tip. The modification consists of a modified chamfer $0.6 \times 45^{\circ}$ at the tool tip. CSN 12050.1. steel was chosen as the workpiece material. In the experiment durability is determined by measuring the wear on the back of the tool. When tool wear reaches the criterial value, the value of tool life is deducted. Later in the experiment a rotary dynamometer will be used to measure cutting forces. A recording of cutting forces is made to observe, how the distribution of forces changes due to modification of the tool geometry. The tested tools are a part from the tip modification, identical they have the same deposited thin layer, substrate and microgeometry.

\section{Determination of tool time in cutting process}

Before initiation of the test, the length of time for milling was set at 5 minutes. After this tool wear is measured using a microscope. In the planning stage it is important to specify the means of measuring the wear, because by measuring wear tool durability is established. Before measuring the cutting edges of the tools must be documented. Because wear reduces the amount of edge material, it is necessary to create a mask (Fig. 1) of the original blade. The mask is attached to the worn milling tool. From this mask are measured values of wear. The mask is formed from three lines that follow the contour of the cutter on the tip.

Before measuring, the location for measuring wear is determined on the cutter edge on the cylindrical part at the point of the tool tip. This section was chosen because of the expected wear on the tip. For monitoring wear and the value of criterial wear was found to be VBcritical $=250 \mu \mathrm{m}$

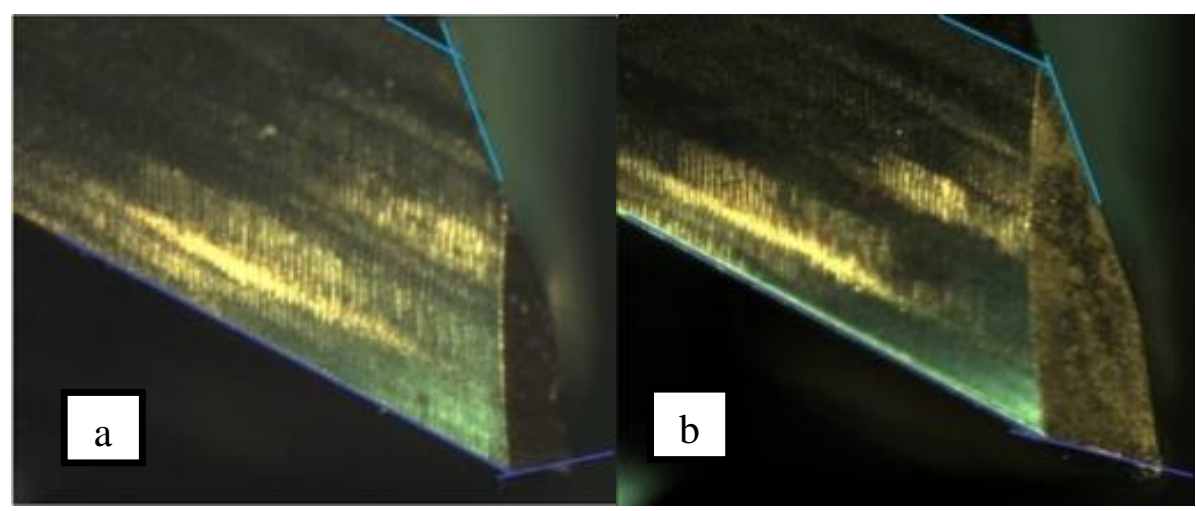

Fig. 1. Mask on tool (a) sharp (b) with chamfer 


\section{Milling tools}

Four tools were used for the experiment a four-edge frontally cylindrical monolithic type of milling tool made from cemented carbide with a thin layer. Basic tool parameters are shown in Table 1. The tools were marked as "A" without modification and "B" with modified tip chamfer $0.6 \times 45^{\circ}$.

\begin{tabular}{lll}
\hline Tool & A & B \\
\hline Diameter [mm] & 12 & 12 \\
Cutter teeth & 4 & 4 \\
Chamfer tip [mm] & $0.15 \times 45^{\circ}$ & $0.6 \times 45^{\circ}$ \\
Helix $\left[^{\circ}\right]$ & 50 & 50 \\
Length [mm] & 83 & 83 \\
Cutting length [mm] & 26 & 26 \\
\hline
\end{tabular}

Table 1. Basic tool parameters

\section{Milled material}

The milled material was preformed steel CSN 12050.1. This material is carbon structural steel specified for refining and surface hardening. This material was chosen because it is used as a standard material in machinability tests. The semi-finished product was a block of $305 \times 305 \times 152 \mathrm{~mm}$. Before performing the test it was milled to its final dimensions of 296x269x180 mm to remove the heat affected area of the previous cutting. [2,3]

\begin{tabular}{lcccccccc}
\hline $\begin{array}{l}\text { Chemical } \\
\text { element }\end{array}$ & $\mathrm{C}$ & $\mathrm{Mn}$ & $\mathrm{Si}$ & $\mathrm{P} \max$ & $\mathrm{S}$ max & $\mathrm{Cu} \max$ & $\mathrm{Cr} \max$ & Ni max \\
\hline Content [\%] & $0.42-0.5$ & $0.5-0.8$ & $0.17-0.37$ & 0.040 & 0.04 & 0.3 & 0.25 & 0.3 \\
\hline
\end{tabular}

Table 2. Chemical composition of steel 12050.1 [3]

\section{Experiment}

A long-term durability test was carried out on all four milling tools. The test was performed under constant conditions that were determined before the start of the experiment using the cutting conditions recommended by the tool manufacturers. The material was machined by each tool according to a predefined procedure for constant cutting speed. After specified time intervals wear was measured on the back. After reaching the prescribed wear criteria tool durability was evaluated.

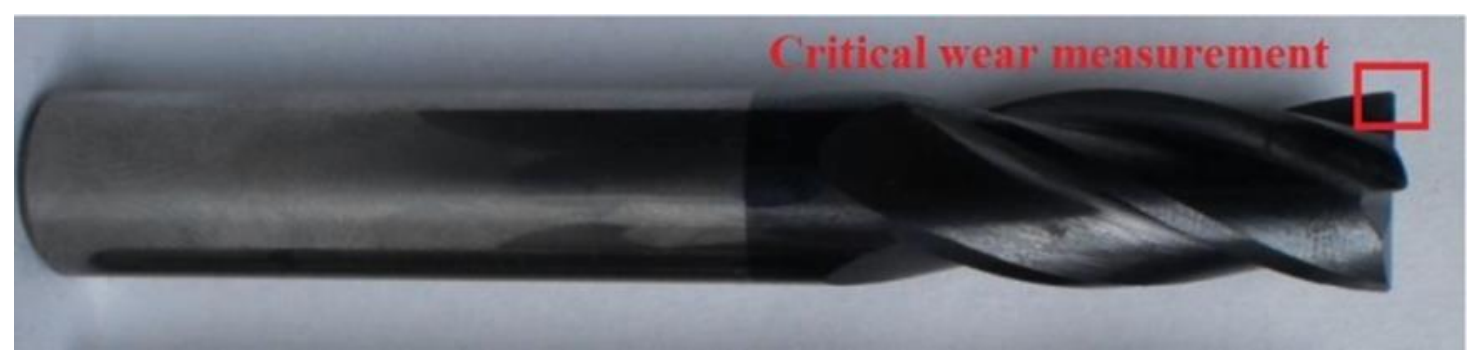

Fig. 2. Measured wear location

Wear measurements were always taken on all four cutting edges. At the beginning of each measurement one edge is defined as the first edge, and from this the other blades are measured in a clockwise direction. This ensures that edges are measured in the same sequence and the first edge is always first throughout the testing. Wear is measured at the point of the tip.

\section{Long term testing of tool type A}

\subsection{Long term testing of tool A1}

Tool types A were machined under constant cutting conditions specified in the experiment. The wear values measured during machining are shown in Tab. 3. 


\begin{tabular}{ccccccc}
\hline \multicolumn{7}{c}{ Tool A1 } \\
\hline $\mathrm{T}_{1}$ & $\Delta \mathrm{t}[\mathrm{min}]$ & $\mathrm{VB}_{1}[\mu \mathrm{m}]$ & $\mathrm{VB}_{2}[\mu \mathrm{m}]$ & $\mathrm{VB}_{3}[\mu \mathrm{m}]$ & $\mathrm{VB}_{4}[\mathrm{~mm}]$ & $\mathrm{VB}_{\text {st̆ }}[\mu \mathrm{m}]$ \\
$\mathrm{T}_{2}$ & 5.17 & 25 & 21 & 30 & 19 & 24 \\
$\mathrm{~T}_{3}$ & 5.98 & 41 & 32 & 30 & 25 & 32 \\
$\mathrm{~T}_{4}$ & 4.83 & 46 & 46 & 43 & 28 & 41 \\
$\mathrm{~T}_{5}$ & 5.17 & 83 & 232 & 73 & 209 & 149 \\
$\mathrm{~T}_{6}$ & 4.97 & 179 & 303 & 129 & 222 & 208 \\
$\mathrm{~T}_{7}$ & 5 & 394 & 289 & 255 & 319 & 314 \\
\hline
\end{tabular}

Table 3. Measured wear of tool A1

Machining with this tool until the 15th minutes the wear had only a slightly increasing character, shown in Fig. 4. The low increase of wear was manifested by acoustic emissions, when the machining process was without the presence of high and low tones. After that there was an exponential increase of wear. Even if the increase of the wear was sudden, wear on the cutting edge was steady without plastic deformation. Increases of wear were manifested in acoustic emissions. Audible tones could be heard in connection with the instability of the milling process, such as high tones. They were indicated by oscillations of the machine followed by vibration to the floor. From the 25th to 35th minute the tool emitted high tones associated with significant wear. The tool reached criteria wear after 32 minutes.

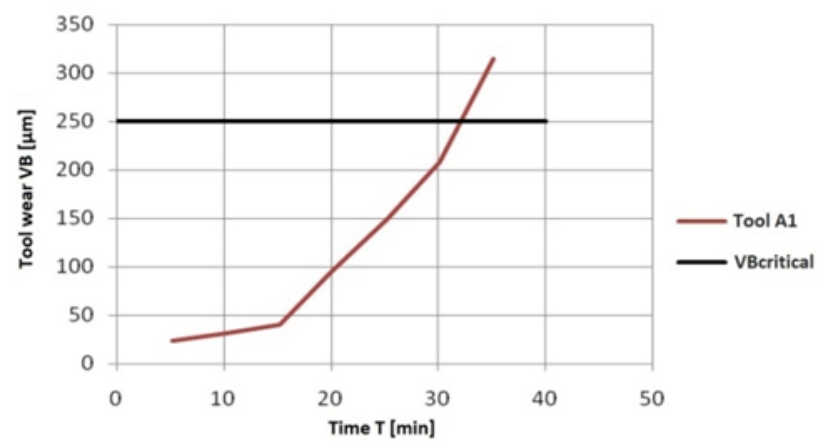

Fig. 3. Wear dependence of tool A1

The tool wear occurred equally on the back and at the head of the tool. The material does not adhere in the tooth space of the milling tool. In the last 5 minutes of milling, wear caused more heat and chips left the cutting process in a red hot state. At the beginning of each interval cutting forces were measured. The change in cutting forces is shown in Fig. 4. As expected, the highest levels were reached by cutting forces Fx and Fy and the increase of cutting forces was steady.

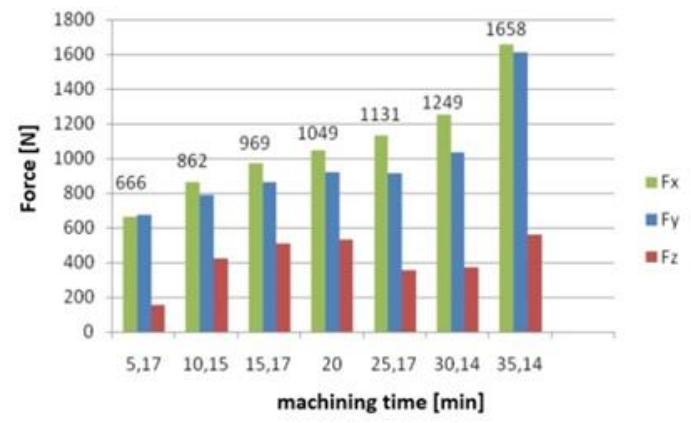

Fig. 4. The change of cutting forces during long-term testing of tool A1

\subsection{Long term testing of tool A2}

Tool A2 was also machined at intervals of 5 minutes. Before starting the testing, chucks were changed and therefore cutting forces were not measured, because the dynamometer is not equipped with hydraulic clamping tools. Measured values are shown in Tab. 4. 


\begin{tabular}{ccccccc}
\hline \multicolumn{7}{c}{ Tool A2 } \\
\hline $\mathrm{T}_{1}$ & $\Delta \mathrm{t}[\mathrm{min}]$ & $\mathrm{VB}_{1}[\mu \mathrm{m}]$ & $\mathrm{VB}_{2}[\mu \mathrm{m}]$ & $\mathrm{VB}_{3}[\mu \mathrm{m}]$ & $\mathrm{VB}_{4}[\mathrm{~mm}]$ & $\mathrm{VB}_{\text {str }}[\mu \mathrm{m}]$ \\
$\mathrm{T}_{2}$ & 4.98 & 30 & 27 & 25 & 26 & 27 \\
$\mathrm{~T}_{3}$ & 5.92 & 67 & 41 & 40 & 62 & 53 \\
$\mathrm{~T}_{4}$ & 7.5 & 143 & 249 & 136 & 117 & 161 \\
$\mathrm{~T}_{5}$ & 5.13 & 241 & 283 & 253 & 141 & 230 \\
$\mathrm{~T}_{6}$ & 5.12 & 304 & 332 & 350 & 320 & 327 \\
$\mathrm{~T}_{7}$ & 4.77 & 377 & 347 & 461 & 290 & 369 \\
$\mathrm{~T}_{8}$ & 4.98 & 443 & 385 & 445 & 382 & 414 \\
\hline
\end{tabular}

Table 4. Measured wear of tool A2

This tool reached criteria value of wear after approximately 30 minutes. Wear up to 20 minutes increased slowly to $130 \mu \mathrm{m}$, but then rapid increase of wear occurred. A change to the clamping was expected to increase the rigidity and thereby increase the durability of tool. However, the tool showed the lowest durability from the tested tools without modified tool tip.

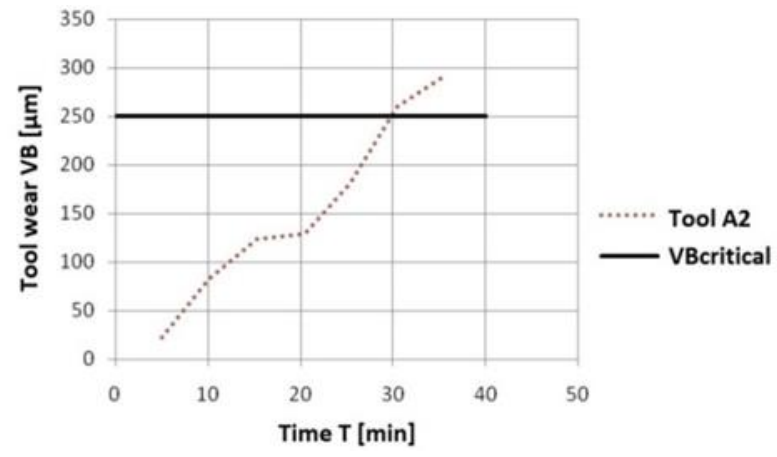

Fig. 5. Wear dependence of tool A2

Up to the 25th minute wear with an abrasive character was formed on the cutting edge. At this time instability of the cutting process started, which was manifested by acoustic emissions. Deep tones were emitted which moved into the base of the machine. Tool wear also caused high tones. Furthermore, the wear was reflected by red hot chips flying up. Hot chips are a manifestation of raised temperature in the cutting location and therefore wear on the cutting edge can be regarded as a brittle fracture of small pieces of edge.

\subsection{Long term testing of tool B1}

Tool types B1 were machined under the constant cutting conditions specified in the experiment. The wear values measured during machining are shown in Tab. 5.

\begin{tabular}{ccccccc}
\hline \multicolumn{7}{c}{ Tool B1 } \\
\hline $\mathrm{T}_{1}$ & $\Delta \mathrm{t}[\mathrm{min}]$ & $\mathrm{VB}_{1}[\mu \mathrm{m}]$ & $\mathrm{VB}_{2}[\mu \mathrm{m}]$ & $\mathrm{VB}_{3}[\mu \mathrm{m}]$ & $\mathrm{VB}_{4}[\mathrm{~mm}]$ & $\mathrm{VB}_{\text {s̆r }}[\mu \mathrm{m}]$ \\
$\mathrm{T}_{2}$ & 4.77 & 22 & 21 & 20 & 20 & 21 \\
$\mathrm{~T}_{3}$ & 5.02 & 41 & 43 & 37 & 30 & 38 \\
$\mathrm{~T}_{4}$ & 5.98 & 49 & 62 & 78 & 65 & 64 \\
$\mathrm{~T}_{5}$ & 5.28 & 89 & 117 & 109 & 106 & 105 \\
$\mathrm{~T}_{6}$ & 5.07 & 173 & 201 & 205 & 127 & 177 \\
$\mathrm{~T}_{7}$ & 4.97 & 195 & 272 & 244 & 157 & 217 \\
$\mathrm{~T}_{8}$ & 4.53 & 396 & 507 & 327 & 308 & 385 \\
\hline
\end{tabular}

Table 5. Measured wear of tool B1

This tool reached criteria value of wear after approximately 36 minutes. The values of wear measured during machining relative to time are shown in Fig. 6. Wear up to 25 minutes slowly increased to $130 \mu \mathrm{m}$. Up to this moment, 
the tool did not exhibit any significant acoustic emissions, but then rapid increase of wear occurred. Low and high tones began, caused by tool wear. In comparison with the other tools without modified tips, this tool showed a lower intensity of acoustic emission. [5]

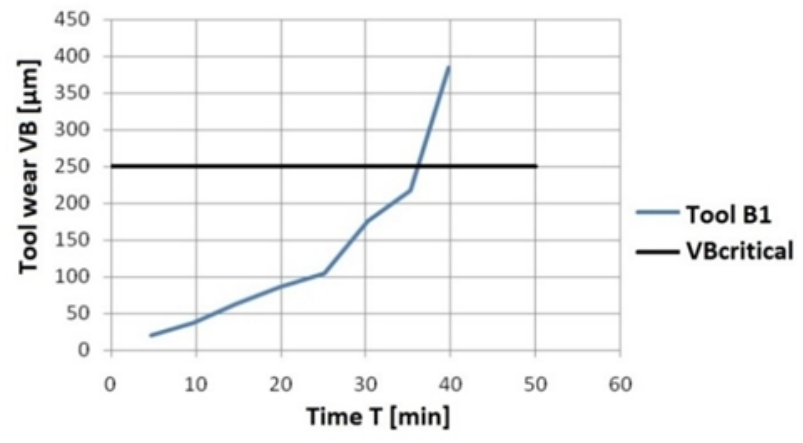

Fig. 6. Wear dependence of tool B1

During the machining the cutting edge of the tool wore equally on the face and on the back of the edge throughout the depth of cut. Until 25 minutes the wear had an abrasive character. Then with increasing temperature and pressure and the action of adhesion, brittle fracture of the edge and crumbling of the blade began. Increase of the wear was also reflected in the colour of the chips, which flew off as incandescent chips.

Cutting forces were measured in this tool. It was assumed that the chosen modification of the tip would be reflected in the cutting forces. This modified tool showed higher cutting forces at the beginning of the process. The difference between cutting forces measured on unmodified tools and tools with modified tips was 100N. [5]

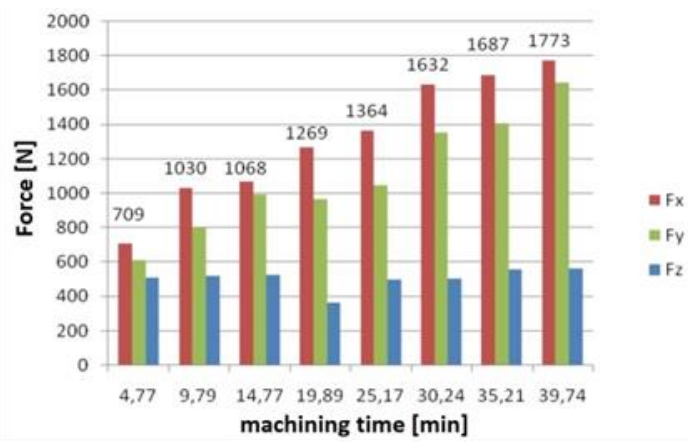

Fig. 7. The change of cutting forces during long-term testing of tool B1

\subsection{Long term testing of tool B2}

Before starting testing chucks were changed and therefore cutting forces were not measured, because the dynamometer is not equipped with a clamping tool. Measured values are shown in Tab.6.

\begin{tabular}{ccccccc}
\hline \multicolumn{7}{c}{ Tool B2 } \\
\hline $\mathrm{T}_{1}$ & $\Delta \mathrm{t}[\mathrm{min}]$ & $\mathrm{VB}_{1}[\mu \mathrm{m}]$ & $\mathrm{VB}_{2}[\mu \mathrm{m}]$ & $\mathrm{VB}_{3}[\mu \mathrm{m}]$ & $\mathrm{VB}_{4}[\mathrm{~mm}]$ & $\mathrm{VB}_{\text {str }}[\mu \mathrm{m}]$ \\
$\mathrm{T}_{2}$ & 4.98 & 30 & 27 & 25 & 26 & 27 \\
$\mathrm{~T}_{3}$ & 5.92 & 67 & 41 & 40 & 62 & 53 \\
$\mathrm{~T}_{4}$ & 7.5 & 143 & 249 & 136 & 117 & 161 \\
$\mathrm{~T}_{5}$ & 5.13 & 241 & 283 & 253 & 141 & 230 \\
$\mathrm{~T}_{6}$ & 5.12 & 304 & 332 & 350 & 320 & 327 \\
$\mathrm{~T}_{7}$ & 4.77 & 377 & 347 & 461 & 290 & 369 \\
$\mathrm{~T}_{8}$ & 4.98 & 443 & 385 & 445 & 382 & 414 \\
\hline
\end{tabular}

Table 6. Measured wear of tool B2

This tool reached criteria value of wear after approximately 29 minutes. Wear had a linear character. It was assumed that changing the clamping device would increase the rigidity and thereby increase the durability of the tool. 
The tool showed the lowest durability from the tested tools with modified tips. Based on this comparison it can be said in this case, that the hydraulic clamping device may not have a greater rigidity than the collet chuck.

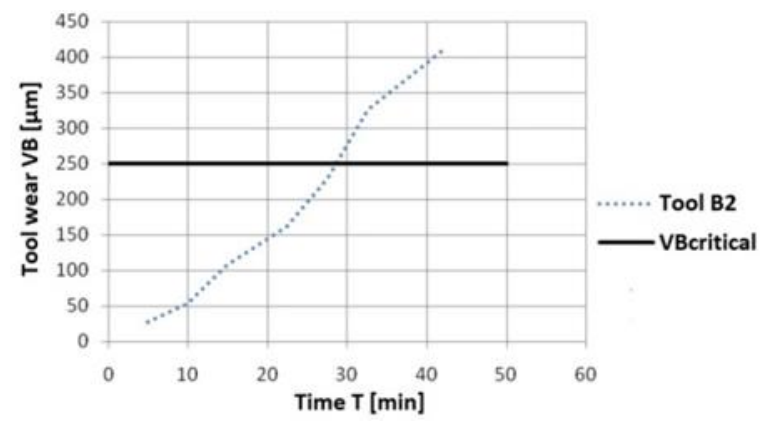

Fig. 8. Wear dependence of tool B2

Up to the 20th minute there is wear on the cutting edge with abrasive character. Instability of the cutting environment began to be manifested by acoustic emissions after 35 minutes in the cut, even if significant tool wear occurred at earlier intervals. This delay of unstable cutting is caused by the modified tip geometry. Although the tool has reached criteria of wear, further machining is possible. After 35 minutes deep acoustic tones started which moved into the base of the machine. There were also high tones from tool wear. Furthermore, the wear was also reflected on the chips, which began flying up as hot splinters.

\section{Evaluation of measured values}

Long-term durability tests were conducted on two types of tools. Conditions were specified on the basis of the recommendations of the manufacturers of the cutting tools. After each time interval wear was measured on the back of edge. Graphs of wear dependent on the time of the milling process were compiled, and the durability for each selected tool for criterial wear VBcriterial was evaluated. The wear of tools was measured at the same location for each blade. Tab. 7 shows the values reached of maximum wear of individual tools and the time at which these values were reached. [8]

\begin{tabular}{lcc|cc}
\hline \multirow{2}{*}{ Tool } & \multicolumn{2}{c|}{ A } & \multicolumn{2}{c}{ B } \\
\cline { 2 - 5 } & 1 & 2 & 1 & 2 \\
\hline Tcrit $[\min ]$ & 32 & 30 & 36 & 28 \\
VBmax $[\mu \mathrm{m}]$ & 314 & 291 & 385 & 414 \\
$\mathrm{~T}_{\text {celk }}[\min ]$ & 35,14 & 35,56 & 39,74 & 42,42 \\
\hline
\end{tabular}

Table 7. Long-term test values

Dependence of the wear on time of milling is shown in Fig. 8. All tools reached their criteria wear. Two more time intervals were milled with tool B2, because its acoustic emissions did not suggest enough blunting to eliminate the tool from the test. Fig. 9 shows a comparison of all the tools. It is obvious that tool B1 achieved the highest durability. This tool reached criteria wear approximately after 38 minutes. This tool did not exhibit wear by brittle fracture or by plastic deformation, but it had an abrasive character. [9]

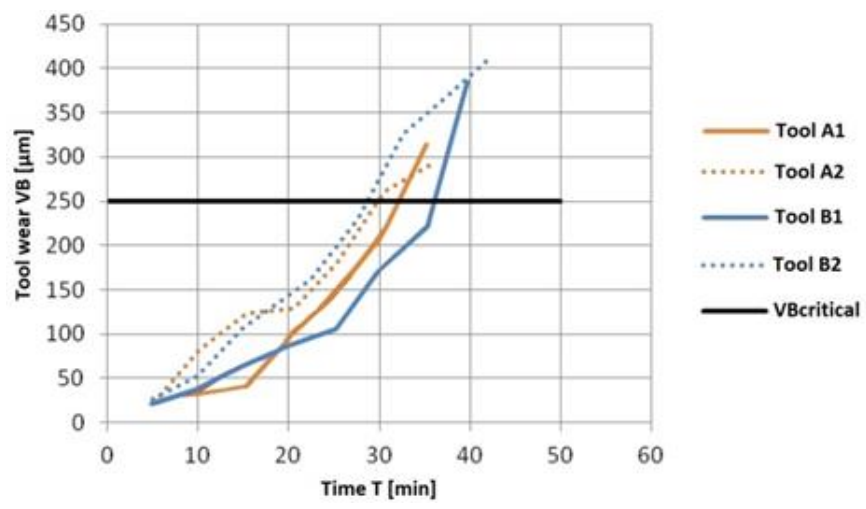

Fig.9. The progress of wear all measured tools 
Tools A2 and B2 reached the lowest value of durability. Both of these tools were used with a different clamp from the other tools and it is probable that this change and the reduction of durability are related. The clamp used for these two tools was hydraulic. For this experiment it was presumed, that the stiffness of the hydraulic clamping device would be more rigid than the collet fixture. According to the results of the experiment, the hydraulic clamp is less rigid than the chuck collet. An interesting finding is that the ratio of the durability of tools with modified and unmodified tips was opposite to the clamping with the rigid collet. The tools with modified tips exhibit lower durability than unmodified tools. It is possible that the rigidity could significantly influence the outcomes of the experiment. It was also interesting that tool B2 reached criteria wear in the lowest time, but its character was still favourable for continuing with the machining process. After machining with this tool for 25 minutes there were no red hot chips or an unstable cutting process manifested by acoustic emissions. Therefore, machining was continued in order to utilize the potential of the tool until it was totally blunt. $[4,6]$

\section{Conclusion}

In this research an experiment was carried out dealing with the suitable choice of tool geometry, especially focusing on the effects of modified tips on tool durability. The aim was to compare two types of monolithic tools in terms of their durability. However, this occurred only for the last two tested tools, with a change of chucks. But at the end of testing it was found that rigidity of clamping affects tool durability. From the results it can be seen that changing chucks reduces the durability of the tools. For modified tools, the durability was even lower than for tools without modification. The main idea of the experiment was to measure the wear on the back of the tool at specified time intervals. Graphs were compiled from the results of the measurements, showing wear relative to time for each tool. Then the durability for specific criterial wear was evaluated. The greatest durability was achieved by a tool with a modified tip, whose durability was 36 minutes, which was about 7 minutes longer than the tool with the lowest durability. [10]

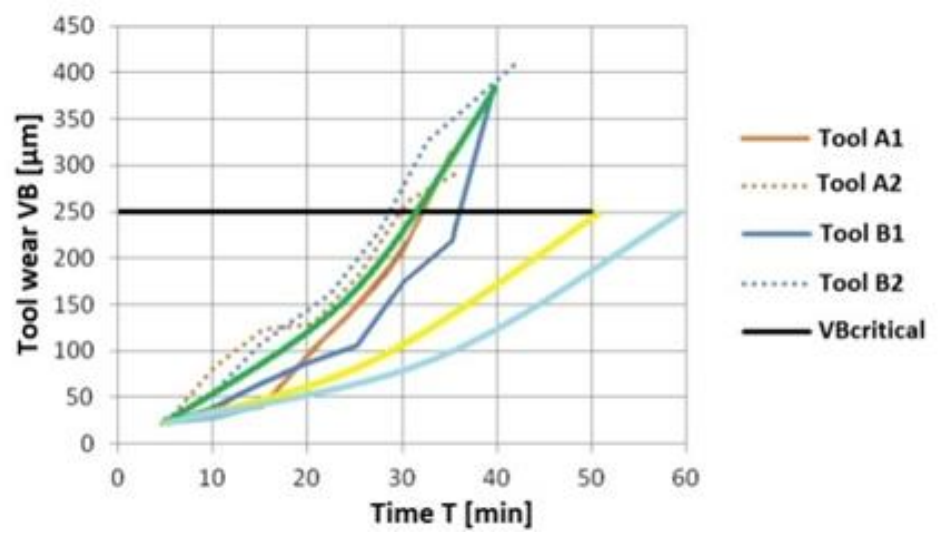

Fig.10. The effect of stiffness

The results of the experiment do not provide an unambiguous confirmation of the initial theory, the cause could be the rigidity of the apparatus. If the equipment is not sufficiently rigid, it will create an unstable cutting process and thereby consequently reduce the durability of the tools. If the effects connected with excessive tip wear were observed in a system with higher stiffness, this effect may not necessarily occur in a system with lower stiffness. Fig. 10 describes the state where, if the experiment were performed on a system with higher rigidity, this could lead to increased tool durability, shown by the blue and yellow curve on the right side of the graph. The green curve could represent the state of rigidity when tools with and without modifications have the same durability, or where the application of modifications provide the same advantages as disadvantages in terms of wear during the process of tool wear. If the rigidity of the system is decreased, the location of wear moves to the left of the green curve. Here the tool with a modified tip has lower durability than the tool without modification. The rigidity of the system may cause the original theory to be rejected. In further testing the impact of feed rate should also be taken into account.

The hypothesis which we were tasked to verify in this experiment seems to be real and has not been rejected from a statistical point of view. Due to the limited quantity of tools available for testing, this experiment could be taken as an orientation test, which could be the first stage for further research in the investigation of increasing durability of tools by tip modification. The causes may be quite different, and if we do not repeat the experiment with significantly more samples, we cannot provide a clear explanation. [7]

\section{Acknowledgements}

This paper is based upon work sponsored by project SGS-2013-031. 


\section{References}

[1] HUMÁR, Anton. TECHNOLOGIE I [online]. Brno, 2003 [cit. 2015-06-21] Available from: http://ust.fme.vutbr.cz/obrabeni/opory-save/TI_TO-1cast.pdf

[2] BOLZANO C45 [online]. $2015-07-19]$ from:http://www.bolzano.cz/assets/files/TP/MOP_\%20Tycova_ocel/EN_10083/MOP_vlastnosti_C45.pdf

[3] ČSN 12050 [online]. [cit. 2015-07-19]. Available from: http://www.preciz.cz/sluzby-hlavni/materialnormal/1.1191.

[4] Vopat. T.; Peterka. J.; Kovac. M.; Buransky. I.:The Wear Measurement Process of Ball Nose End Mill in the Copy Milling Operations, Annals of 24th DAAAM International Symposium on Intelligent Manufacturing and Automation, 2013,Procedia Engineering, Volume 69, 2014, Pages 1038-1047, Published by DAAAM International Vienna, Vienna.

[5] Belan, M. \& Michalik, P.: The Durability and Wear of Coated Mills from HSS-PM in Stainless Steel Cutting without Cutting Fluid, Annals of DAAAM for 2012 \& Proceedings of the 23rd International DAAAM Symposium, Volume 23, No.1, ISSN 2304-1382 ISBN 978-3-901509-91-9, CDROM version, Ed. B. Katalinic, Published by DAAAM International, Vienna, Austria, EU, 2012.

[6] Jozic, S.; Bajic, D. \& Topic, S.: Flank Wear in Down and Up Milling Annals of DAAAM for 2012 \& Proceedings of the 23rd International DAAAM Symposium, Volume 23, No.1, ISSN 2304-1382 ISBN 978-3-901509-91-9, CDROM version, Ed. B. Katalinic, Published by DAAAM International, Vienna, Austria, EU, 2012.

[7] Zhou.L;Peng.Y;Yan.R;Yao.P.F;Yang.C.C;Li.B: Analytical modeling and experimental validation of micro endmilling cutting forces considering edge radius and material strengthening effects International Journal of Machine Tools and Manufacture, Volume 97, October 2015, Pages 29-41.

[8] K.S. Woon, M. Rahman, K.S. Neo, K. Liu: The effect of tool edge radius on the contact phenomenon of toolbased micromachining, Int. J. Mach. Tools Manuf., 49 (2009), pp. 865-875.

[9] M. Kulenovic, D. Begic, A. Cekic, Experimental investigation of carbon steel in high speed cutting, Annals of DAAAM for 2007 \& Proceedings of the 18th International DAAAM Symposium, Published by DAAAM International, Vienna, 2007, pp. $411-412$.

[10] B. Denkena, T. Grove, M. Rehe, B. Bergmann, Material specific cutting edge geometries for machining processes, Proceedings of the 11th International Conference on High Speed Machining, (September 2014), ISBN 978-80904077-7-0, 1-8. 